\title{
A rare cause of a cholestatic jaundice in a North African teenager
}

Schreiner, Philipp ; Stieger, Bruno ; McLin, Valérie ; Rougemont, Anne-Laure ; Keitel, Verena ; Dröge, Carola ; Müllhaupt, Beat

\begin{abstract}
We report an unusual case of intermittent episodes of cholestasis in a young patient. The cholestatic attacks were preceded in each case by an infection and subsequent antibiotic therapies. After ruling out many possible causes of cholestatic hepatitis, the differential diagnoses were a benign recurrent intrahepatic cholestasis or a drug-induced liver injury. We discuss here the diagnostic approach and interpretation of the genetic analysis.
\end{abstract}

DOI: https://doi.org/10.1111/liv.14122

Posted at the Zurich Open Repository and Archive, University of Zurich ZORA URL: https://doi.org/10.5167/uzh-179693

Journal Article

Accepted Version

Originally published at:

Schreiner, Philipp; Stieger, Bruno; McLin, Valérie; Rougemont, Anne-Laure; Keitel, Verena; Dröge, Carola; Müllhaupt, Beat (2019). A rare cause of a cholestatic jaundice in a North African teenager. Liver International, 39(11):2036-2041.

DOI: https://doi.org/10.1111/liv.14122 


\title{
A rare cause of a cholestatic jaundice in a North African teenager
}

\author{
Philipp Schreiner $\mathrm{MD}^{1}$; Bruno Stieger $\mathrm{PhD}^{2}$, Valérie McLin MD ${ }^{3}$, Anne-Laure
} Rougemont $^{4}$, Verena Keitel MD ${ }^{5}$, Carola Droege ${ }^{5}$, Beat Müllhaupt MD ${ }^{1}$

\author{
1 Division of Gastroenterology and Hepatology, University Hospital of Zurich, Zurich, Switzerland \\ 2 Division of Clinical Pharmacology and Toxicology, University of Zurich, Zurich, Switzerland \\ ${ }^{3}$ Pediatric Gastroenterology Unit, Childrens's Hospital, University Hospitals Geneva, Geneva, Switzerland \\ ${ }^{4}$ Department of Genetic and Laboratory Medicine, Division of Clinical Pathology, University Hospitals Geneva, \\ Geneva, Switzerland \\ ${ }^{5}$ Division of Gastroenterology and Hepatology, University Hospital of Duesseldorf, Duesseldorf, Germany
}

\section{Corresponding author:}

Prof. Dr. med. Beat Müllhaupt

Klinik für Gastroenterologie und Hepatologie

Universitätsspital Zürich

Rämistrasse 100

$\mathrm{CH}-8091$ Zürich

Switzerland

beat.müllhaupt@usz.ch

\section{Conficts of interest:}

The authors hereby state no conflicts of interest.

\section{Key words:}

benign recurrent intrahepatic cholestasis

\section{Abbreviations:}

ALT: alanine transaminase

AST: aspartate aminotransferase

BRIC: benign recurrent intrahepatic cholestasis

GGT: gamma-glutamyl transferase

PFIC: progressive familial intrahepatic cholestasis 
Introduction

Cholestasis is caused by a failure of one or more steps involved in bile production and leads to an elevation of bile constituents in blood ${ }^{1,2}$. Clinically, cholestasis is associated with elevated serum bile salts, jaundice and pruritus. Cholestasis may be acquired or inherited. The latter forms of cholestasis are rare clinical entities and may present as severe progressive familial intrahepatic cholestasis (PFIC), as benign recurrent intrahepatic cholestasis (BRIC) as well as different cholestatic syndromes ranging from gallstone disease and intrahepatic cholestasis of pregnancy to liver fibrosis and cirrhosis ${ }^{3-5}$. Currently, mutations in several genes are known to cause inherited cholestatic syndromes by affecting canalicular bile formation: the best studied ones include ATP8B1 (encoding the canalicular aminophospholipid translocator ATP8B1 or FIC1), ABCB11 (encoding the canalicular bile salt export pump BSEP) and $A B C B 4$ (encoding the canalicular phosphatidylcholine translocator MDR3). In addition mutations in TJP2 (encoding the tight junction protein 2 TJP2, which is a cytosolic component of tight junctions), NR1H4 (encoding the transcription factor and bile salt sensor $\mathrm{FXR}$ ) and $M Y O 5 B^{6}$ also lead to cholestatic syndromes, albeit at a much lower incidence than the first three types ${ }^{7}$. 


\section{Case Report}

A 16-year-old male Moroccan teenager presented to the emergency department with acuteonset jaundice. The patient had been healthy until a few days before when he began to vomit repeatedly, presented with abdominal cramping and felt very fatigued. He sought medical care after noticing jaundice and developing severe pruritus.

On physical examination the patient was deeply jaundiced, afebrile and normotensive. The abdomen was soft without tenderness. The rest of the examination was unremarkable; and there was no sign of encephalopathy.

The blood results revealed a markedly elevated total bilirubin $(264 \mu \mathrm{mol} / \mathrm{l}$, ref $<17 \mu \mathrm{mol} / \mathrm{l})$, with a conjugated fraction of $232 \mu \mathrm{mol} / \mathrm{l}(\mathrm{ref}<7 \mu \mathrm{mol} / \mathrm{l})$, elevated alanine aminotransferase (149 U/I, ref < $40 \mathrm{U} / \mathrm{I})$ and aspartate aminotransferase (52 U/l, ref $<40 \mathrm{U} / \mathrm{l})$. In contrast to the markedly elevated alkaline phosphatase (534 U/I, ref < $130 \mathrm{U} / \mathrm{l})$ and the raised bile acid (324 $\mu \mathrm{mol} / \mathrm{l}(\mathrm{ref}<10 \mu \mathrm{mol} / \mathrm{l})$, the GGT was in the normal range $(58 \mathrm{U} / \mathrm{l}$, ref $50 \mathrm{U} / \mathrm{l})$. Liver function was well preserved and there were no signs of systemic infection (Lab value Figure 1). Screening tests for viral hepatitis (A, B and C), as well as a HIV, were negative. There was no evidence for Wilson's disease (normal ceruloplasmin and normal 24h urinary copper excretion), alpha-1 antitrypsin disease (MM phenotype), autoimmune hepatitis (no autoantibodies) or celiac disease. Ultrasound revealed a normal, but slightly enlarged liver with patent portal and hepatic veins and a normal hepatic artery Doppler. There was no splenomegaly.

Over the next days bilirubin continued to rise prompting liver biopsy. This showed profound cholestasis with minimal inflammation. The copper in the liver biopsy was slightly elevated (111 $\mu \mathrm{g} / \mathrm{g}$, ref $10-35 \mu \mathrm{g} / \mathrm{g})$, but below the diagnostic threshold of $350 \mu \mathrm{g} / \mathrm{g}$. Nevertheless, an ocular slit-lamp examination was performed, but there was no evidence for Kayser-Fleischer rings. Furthermore, a mutation in the ATP7B Gen was excluded. Increased hepatic copper was interpreted to be secondary to cholestasis. 
Finally, a detailed history with the patient revealed that he was consuming cannabis on a regular basis and had repeatedly experimented with codeine syrup in the months preceding his clinical presentation. He rarely drank alcoholic beverages. Cannabis and codeine use were confirmed on urinary testing. The patient was adopted, so that his family history was not available.

Having ruled out many possible causes of the cholestatic hepatitis, the initial hypothesis was a toxic injury of the liver due to cannabis and the codeine syrup. In the next months bilirubin declined slowly to reach normal range but liver enzymes remained slightly elevated.

Nearly a year later the patient presented again to his family doctor because of tonsillitis for which cefuroxime treatment was initiated. After three days of antibiotic therapy the patient stopped the medication because he felt healthy again. This lead to a relapse of the tonsillitis and simultaneously he developed marked jaundice with a severe pruritus and elevation of the AST, ALT, alkaline phosphatase and GGT. Viral hepatitis was once again excluded and a repeat ultrasound was still unremarkable.

A second liver biopsy was performed during this episode of cholestasis. There was still no sign of autoimmune hepatitis or evidence of chronic liver disease, other than persistence of chronic cholestasis (Fig. 2A). An immunohistochemical staining for BSEP (Fig 2B), MDR3 (Fig 2C), and CD10 (Fig 2D) revealed correct localization of the proteins within the canalicular membrane of hepatocytes. However, BSEP protein expression was remarkably heterogenous and overall rather low. (Fig. 2B). Based on the immunohistochemical results, the suspicion of a bile acid transporter disorder was raised. In addition drug-induced liver injury resulting in cholestasis due to the inhibition of the bile salt export pump was still a possibility.

Meanwhile the patient received fat-soluble vitamins (vitamin A, D, E and K) and ursodeoxycholic acid. After a few weeks bilirubin, AST, ALT and GGT normalized. Alkaline phosphatase remained persistently above the upper limit of normal. But given his age this 
was probably still within normal range owing to bone growth/turnover. After normalization of the liver enzymes the patient improved substantially.

Nearly a year later again, the patient suffered again from tonsillitis that was treated with amoxicillin-clavulanic acid. A few days later he developed a cholestatic jaundice with itching and normal GGT. These recurrent episodes of severe jaundice and itching, the last two triggered by an upper respiratory tract infection and treated with antibiotics were highly suggestive of benign recurrent intrahepatic cholestasis and the genes ATP8B1 (NM_005603), ABCB11(NM_003742.2), ABCB4 (NM_000443) and NR1H4 (NM_001206977.1) were analyzed for known mutations.

The results of the genetic analysis are summarized in Table 1 and in supplementary table 1. In total, 36 polymorphic variants were identified in the four analyzed genes. None of the variants had so far been found to be causative of PFIC or BRIC. None of the variants in $N R 1 H 4$ and $A B C B 4$ had been previously associated with intrahepatic liver disease. Of note, rs319436 and rs222581in ATP8B1 were both homozygous and have been described in a patient with $\mathrm{BRIC}^{8}$. Rs2287622 (p.V444A; homozygous) in $A B C B 11$ is known to be associated with lower protein levels of BSEP and an increased susceptibility to acquired cholestasis ${ }^{9}$. Furthermore, p.A1028A (heterozygous in our patient) was found previously in a patient with $\mathrm{BRIC}^{8}$, in patients with $\mathrm{PFIC} 2^{10}$ and associated with primary intrahepatic stones $^{11}$. In addition, rs414877, rs8632237 and rs497692 have been found in PFIC2 patients and rs497692 was found in a patient with BRIC ${ }^{8}$.

Taken together, and in line with the clinical findings, the variants in $A B C B 11$ suggest a predisposition for "drug induced cholestatic liver injury" (DILI). While the clinical picture is compatible with BRIC, the variants identified in ABCB11 are common polymorphisms. However, the combination of the different polymorphisms together with the common ABCB4 polymorphisms (R652G and I237I) may render the patient more susceptible to the development of cholestasis in response to infections and/or drug treatment. 
In order to obtain more information on the role BSEP and MDR3 in the pathogenesis of the cholestatic episodes, the interaction of the antibiotic cefuroxime with these two canalicular ABC-transporters using a newly established assay system ${ }^{12}$ has been studied. Figure 3 shows that the activities of MDR3 and BSEP were not affected by up to $100 \mu \mathrm{M}$ cefuroxime. 


\section{Discussion}

Benign recurrent intrahepatic cholestasis (BRIC) is a rare autosomal-recessive disorder characterized by recurrent attacks of jaundice and pruritus with symptom-free intervals lasting months to years. Unlike progressive familial intrahepatic cholestasis (PFIC), another hereditary genetic liver disease, BRIC does not progress to end stage liver disease ${ }^{13}$. Although Summerskill and Walsh first described the disease in $1959^{14}$, until now only a few hundred cases have been described in literature ${ }^{15}$. In 1969 Tygstrup developed diagnostic criteria for BRIC that included at least two episodes of jaundice separated by a symptom-free interval lasting several months to years, laboratory values consistent with intrahepatic cholestasis, severe pruritus secondary to cholestasis, liver histology demonstrating centrilobular cholestasis, normal intrahepatic and extrahepatic bile ducts confirmed by cholangiography and the absence of other factors known to be associated with cholestasis ${ }^{16}$.

Little is known about precipitating factors of the cholestatic attacks in BRIC. Although it is assumed that viral infections may be a trigger for an episodes of cholestasis in BRIC ${ }^{17}$, this has not been reported for bacterial infections. Preceding the jaundice, our patient had two episodes of tonsillitis, both treated with antibiotics. However, a pathogen was not found, making a viral infection as likely as a bacterial infection. We postulate that the infection, whether viral or bacterial, acted as a trigger for the BRIC episodes in our patient. A druginduced trigger might also be possible and may have aggravated the syndrome. However, the patient received two different antibiotics (cephalosporin and a $\beta$-lactam antibiotic) with nearly no known cross-reaction between both antibiotic groups ${ }^{18,19}$, which makes a reaction to both agents unlikely. Cefuroxime does not inhibit BSEP, MRP2 or MRP3, but causes an intermediate inhibition of MRP4 ${ }^{20}$ and as shown here has not effect on MDR3(Figure 3). Although Amoxicillin/clavulanic acid is the most common drug associated with DILI' ${ }^{21}$, there is no inhibition of MDR3 activity ${ }^{12}$. Furthermore, amoxicillin does not inhibit any of the transporters and clavulanic acid does not inhibit BSEP22. 
The genetic analysis of four genes (table 1 and supplementary table 1) revealed a complex array of variants. The c. $270 \mathrm{C}>\mathrm{T}$ variant in $A B C B 11$ is a synonymous variant (p.F90F) and has previously been described in two patients (heterocygous) of a Chinese cohort of children with intrahepatic cholestasis ${ }^{10}$. Its allelic frequencies is around $5 \%$ in different populations. One of these patients in the Chinese cohort also presented with p.V444A (Homozygous) and p.A1028A (homozygous). We take this as strong indication that this combination of variants may contribute to BRIC in our patient. The p.V444A variant tends to lower protein expression and is well established to be a risk factor for various forms of acquired cholestatic liver diseases $^{9}$ as exemplified for intrahepatic cholestasis of pregnancy ${ }^{23}$. The p.A1028A variant was found significantly more frequent in patients with primary intrahepatic stones in Chinese individuals ${ }^{11}$ and in an individual with intrahepatic cholestasis of pregnancy ${ }^{23}$. Importantly, this variant may also lead to aberrant splicing ${ }^{24}$. The $p . R 698 \mathrm{H}$ variant was identified in a patient with cholestatic hepatitis due to androgenic steroids and in a patient under the antibiotic trimethoprim-sulfamethaxol ${ }^{25}$. Taken together, the rather low BSEP staining intensity in the biopsy may be explained by the p.V444A and the p.A1028A variants found in our patient and together with the ATP8B1 variants can be indicative of BRIC2. The combination of all variants on the other hand may make this patient susceptible to druginduced liver injury. Interestingly, our patient is homozygous for c.711A in the $A B C B 4$ gene, a synonymous variant which is associated with abnormal liver serum parameters in a large Icelandic cohort $^{26}$. Of note, in a cohort of 35 pediatric subjects with idiopathic gallstones, 34 out of 35 patients were homozygous for this variant and one patient heterozygous ${ }^{27}$. Finally, we point out that at the time of sequencing, analysis of the promoters as well as of the TJP2 gene (leading to PFIC4) ${ }^{7}$ and the Myo5B gene (leading to PFIC 6) ${ }^{6,28,29}$ was not an option. 
Aknowledgements :

The authors thank Dr. M. Deheragoda, King's College Hospital, Institute of Liver Studies, in London, UK, for expert review of the slides and Adriana Euler for expert technical assistance. Bruno Stieger received support from the SNF Center of Competence in Research TransCure (University of Berne, Switzerland). 
Figure 1: Laboratory values course

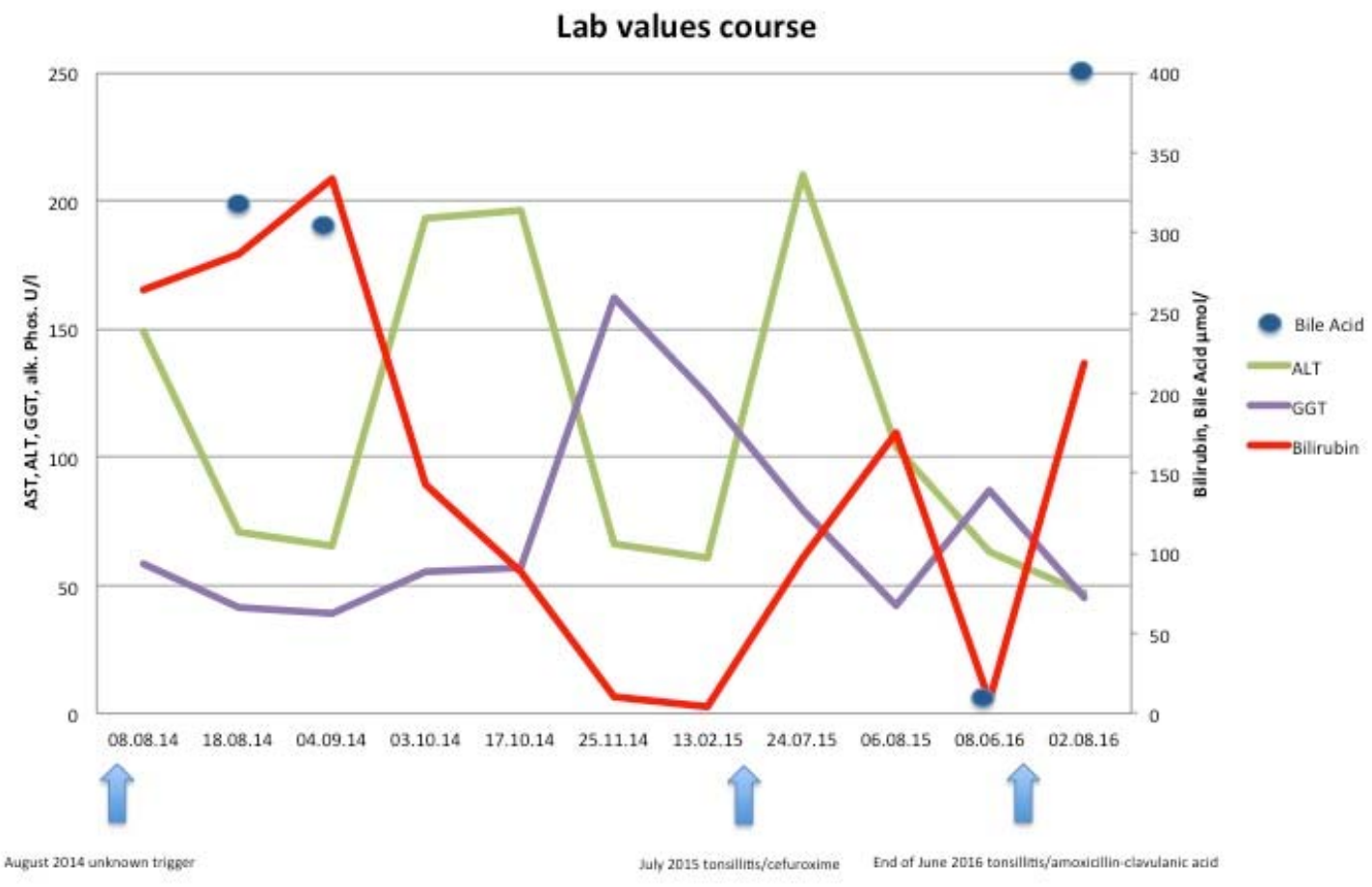


Figure 2A. The lobules show canalicular (arrow) and intrahepatocytic cholestasis

(arrowhead), in the absence of disarray or of significant inflammation (Hematoxylin\&Eosin, original magnification $\times 200)$.

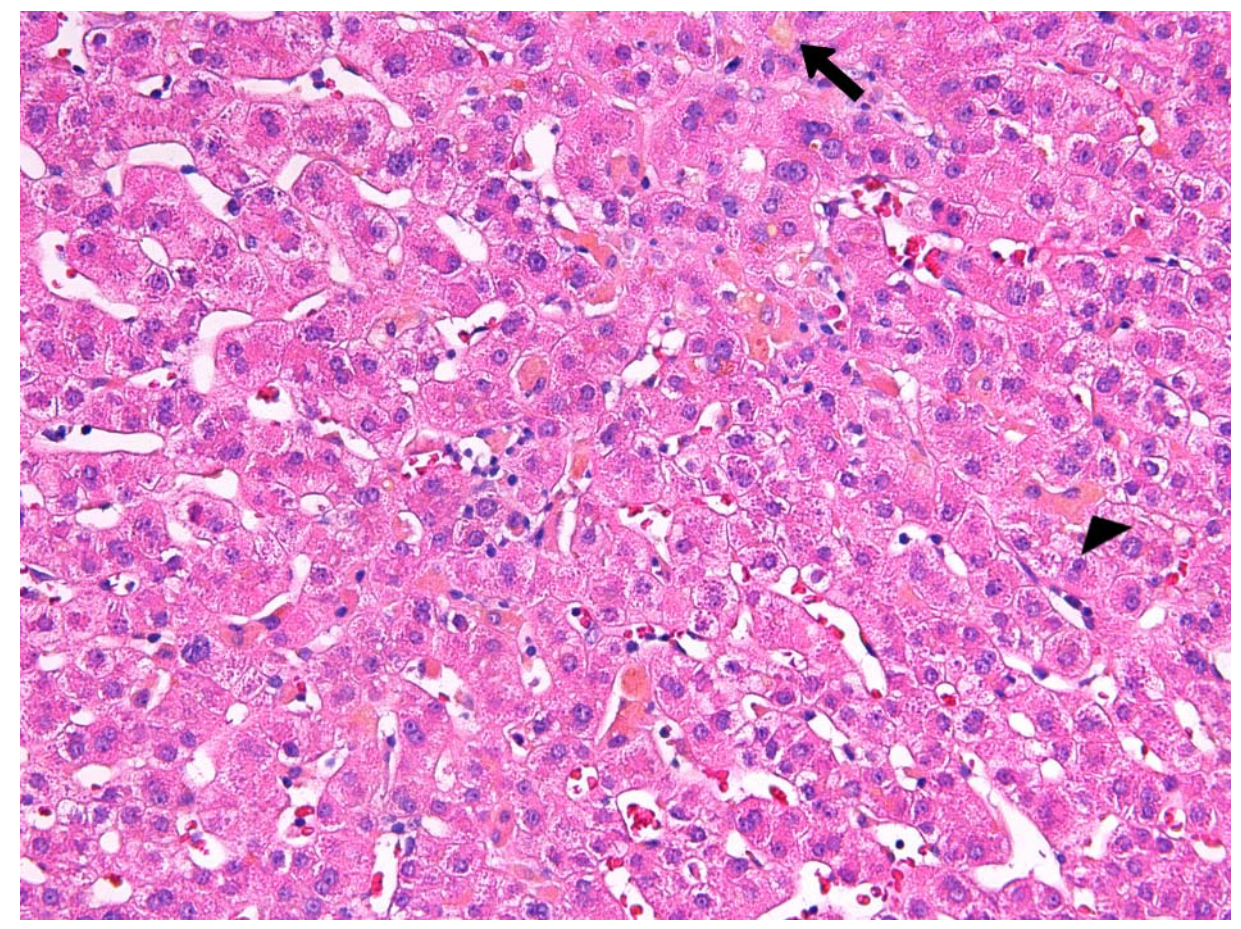


Figure 2B. BSEP expression shows a zonal pattern, retained in periportal areas (arrow) and decreased in pericentrolobular regions (arrowhead) (x100).

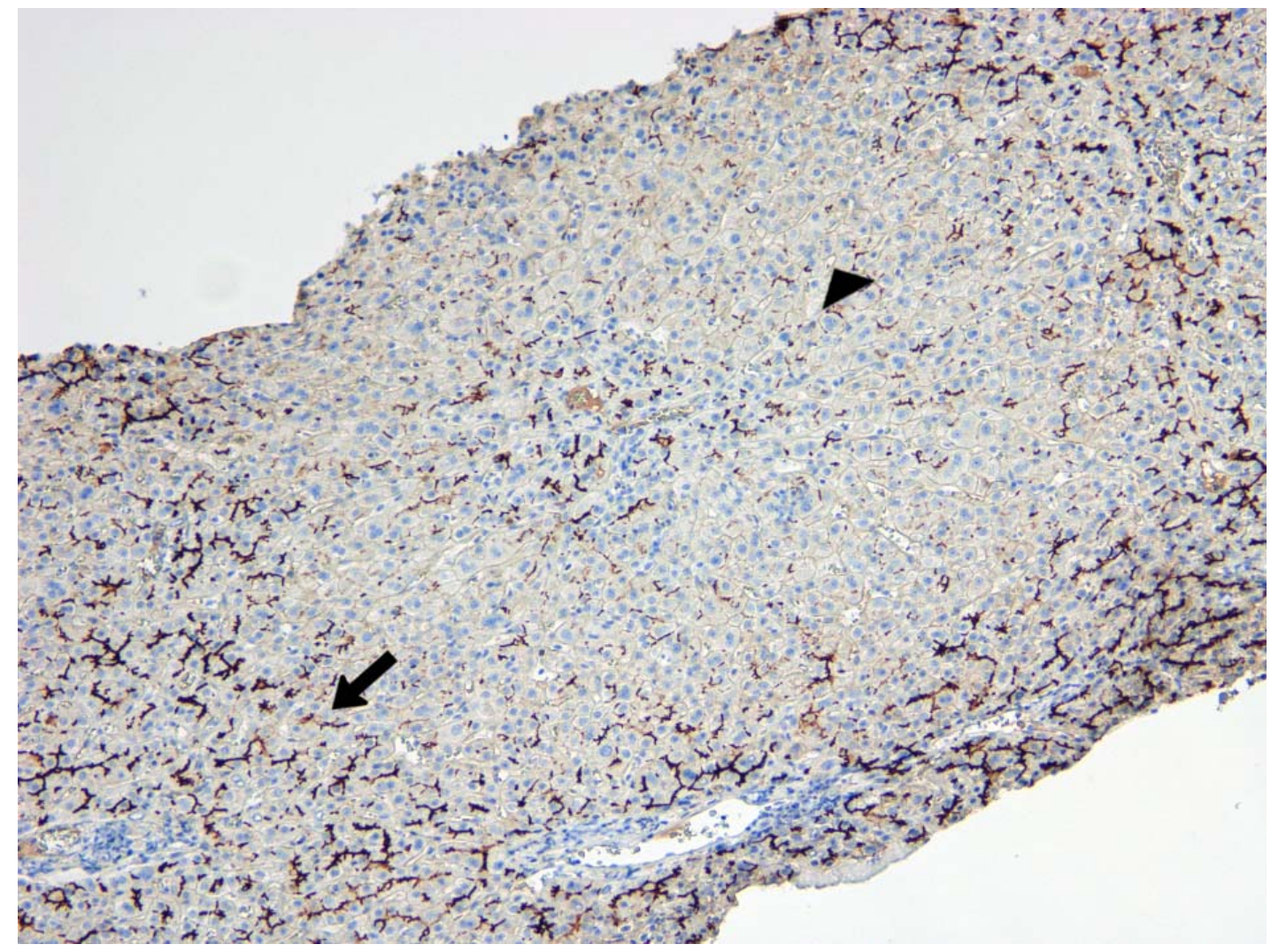


Figure 2C. MDR3 (x100).

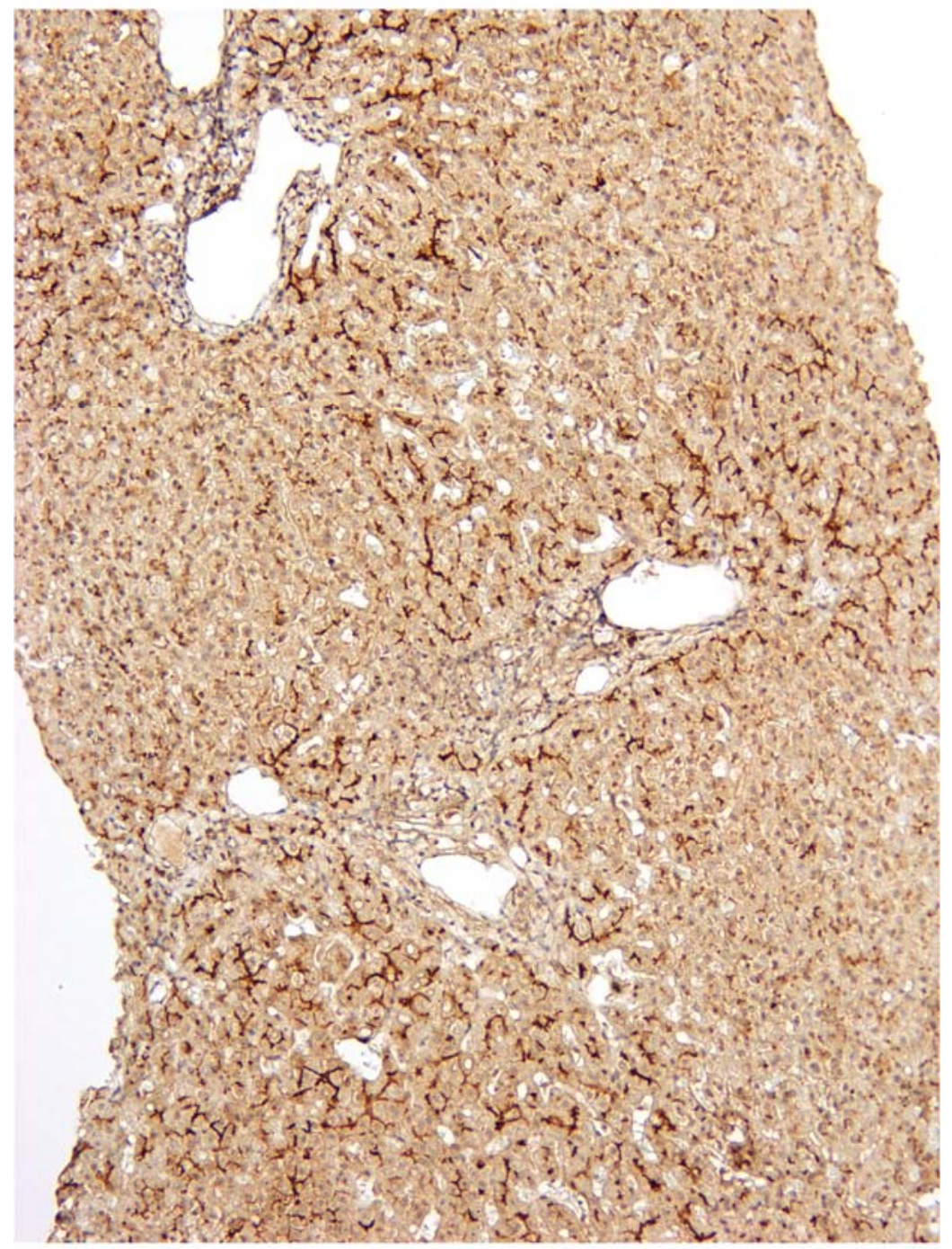


Figure 2D CD10 (x100)

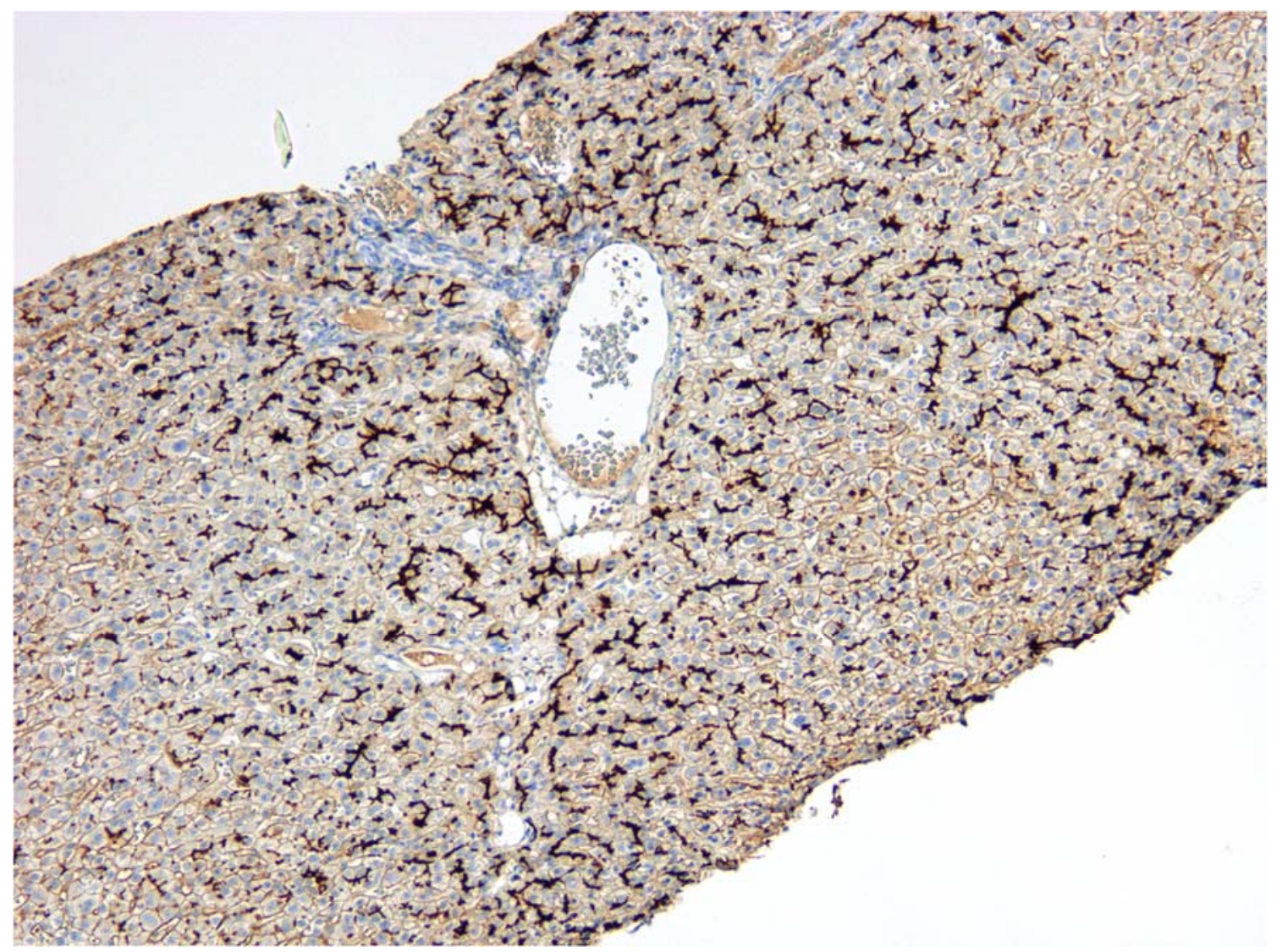

Figure 3: A and B shows TCA transport after 24h incubation with drugs. Monolayers were treated with drugs for $24 \mathrm{~h}$ and transport experiment were started by adding $10 \mathrm{uM} \mathrm{TCA}$ to the basolateral compartment. The effect was assessed by measuring the amount of TCA in the apical compartment after 30 minutes. Shown are two (A and B) independent experiments for $10 \mathrm{uM}$ posaconazole and $100 \mathrm{uM}$ cefuroxime, 1 experiment for $10 \mathrm{uM}$ cefuroxime and WT. The intracellular TCA accumulation was assessed by measuring the amount of TCA from cell lysate, solubilized in $1 \%$ Triton $\mathrm{X}-100$ 
Figure 3 C: C6-NBD-PC secretation after $24 \mathrm{~h}$ incubation with drugs. Monolayers were treated with drugs for $24 \mathrm{~h}$ to assess their effect on MDR3-mediated C6-NBD-PC secretion. Shown are 3 independent experiments for $10 \mathrm{uM}$ posaconazole and 4 experiments for 100 uM cefuroxime and WT.
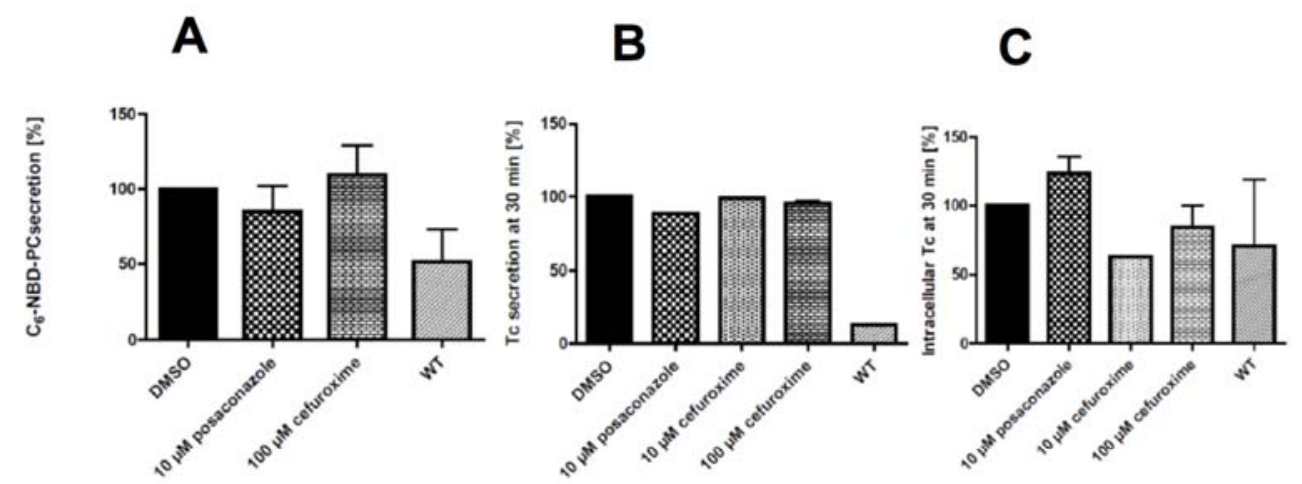
Table 1

\begin{tabular}{|c|c|c|c|c|}
\hline rs number & g. (GRCh38) & c. & p. & AF (\%) all / NFE / AFR \\
\hline \multicolumn{5}{|l|}{ NR1H4 (FXR) } \\
\hline \multicolumn{5}{|c|}{ only non-coding variants } \\
\hline \multicolumn{5}{|l|}{ ATP8B1 (FIC1) } \\
\hline rs319438 (ho) & $57697620 A>G$ * & $696 \mathrm{~T}>\mathrm{C}$ & D232D & $99.8 / 100.0 / 98.0$ \\
\hline rs319443 (ho) & $57695300 \mathrm{~T}>\mathrm{G}$ * & $811 A>C$ & R271R & $99.7 / 100.0 / 97.2$ \\
\hline rs222581 (ho) & $57650444 \mathrm{~T}>\mathrm{C}$ & $3454 A>G$ & A1152T & gDNA vs. transcript \\
\hline \multicolumn{5}{|l|}{ ABCB11 (BSEP) } \\
\hline rs34313070 & 168973871del & 1309-31del & - & $0.2 / 0.01 / 1.9$ \\
\hline rs4148777 & $169013391 A>G$ & $270 \mathrm{~T}>\mathrm{C}$ & F90F & $4.6 / 3.6 / 6.8$ \\
\hline rs2287622 (ho) & $168973818 A>G$ & $1331 \mathrm{~T}>\mathrm{C}$ & V444A & $56.9 / 59.7 / 56.6$ \\
\hline rs138642043 & $168964291 \mathrm{C}>\mathrm{T}$ & $2093 G>A$ & $\mathrm{R} 698 \mathrm{H}$ & $0.4 / 0.3 / 0.7$ \\
\hline rs497692 & $168932506 \mathrm{~T}>\mathrm{C}$ & $3084 A>G$ & A1028A & $54.5 / 53.6 / 26.6$ \\
\hline \multicolumn{5}{|l|}{ ABCB4 (MDR3) } \\
\hline rs2230028 & $87426860 \mathrm{~T}>\mathrm{C}$ & $1954 A>G$ & R652G & $10.5 / 7.5 / 34.8$ \\
\hline rs2109505 & g.87450090T>A & 711A \# & & \\
\hline
\end{tabular}

Detected common intronic variants are listed in Supplementary Table 1.

AF: allele frequency; taken from Genome Aggregation Database (gnomAD), Cambridge, MA (http://gnomad.broadinstitute.org/) [allele frequencies accessed November 2018]. AFs are given for the worldwide (all), Non-Finnish European (NFE) as well as the African population (AFR).

Variants are specified by rs number, exchange on genomic (g.) and coding (c.) DNA level and if applicable on protein level.

Reference sequences:NR1H4: NM_001206977.1; ATP8B1: NM_005603.4; ABCB11: NM_003742.2, ABCB4: NM_000443.3

* in alternative reference sequence AF038007 C-alleles are designated as the reference allele

\# reference allele A represents the risk allele

ho: homozygous 


\section{Supplementary Table 1}

\begin{tabular}{|c|c|c|c|c|}
\hline rs number & g. (GRCh38) & c. & p. & AF (\%) all / NFE / AFR \\
\hline \multicolumn{5}{|l|}{ NR1H4 (FXR) } \\
\hline rs79934001 & $100536486 C>A$ & $733-26 C>A$ & - & $2.7 / 0.2 / 26.2$ \\
\hline rs7138843 & $100536917 T>A$ & $832-31 \mathrm{~T}>\mathrm{A}$ & - & $12.3 / 2.1 / 45.6$ \\
\hline rs11110413 & $100536932 T>A$ & $832-16 \mathrm{~T}>\mathrm{A}$ & - & $4.2 / 0.4 / 36.0$ \\
\hline \multicolumn{5}{|l|}{ ATP8B1 (FIC1) } \\
\hline rs1968274 & $57646979 T>C$ & *1509A>G & - & $25.4 / 20.9 / 28.6$ \\
\hline rs4940950 & $57647588 \mathrm{C}>\mathrm{A}$ & ${ }^{*} 900 \mathrm{G}>\mathrm{T}$ & - & $46.5 / 48.2 / 37.8$ \\
\hline rs4306606 & $57667063 \mathrm{G}>\mathrm{A}$ & $2285+29 \mathrm{C}>\mathrm{T}$ & - & $22.6 / 26.5 / 9.8$ \\
\hline rs317838 & $57671424 \mathrm{G}>\mathrm{A}$ & $1932+44 C>T$ & - & $42.9 / 36.7 / 38.7$ \\
\hline rs317809 & $57691685 \mathrm{G}>\mathrm{A}$ & $1220+122 \mathrm{C}>\mathrm{T}$ & - & $40.8 / 46.2 / 24.5$ \\
\hline rs319439 & $57697598 \mathrm{G}>\mathrm{A}$ & $698+20 C>T$ & - & $48.0 / 47.3 / 26.4$ \\
\hline rs319442 (ho) & $57695584 \mathrm{G}>\mathrm{A}$ & $699-52 C>T$ & - & $99.7 / 100.0 / 97.1$ \\
\hline rs319438 (ho) & $57697620 A>G$ & $696 \mathrm{~T}>\mathrm{C}$ & D232D & $99.8 / 100.0 / 98.0$ \\
\hline rs319443 (ho) & $57695300 \mathrm{~T}>\mathrm{G}$ & $811 A>C$ & R271R & $99.7 / 100.0 / 97.2$ \\
\hline rs222581 (ho) & $57650444 \mathrm{~T}>\mathrm{C}$ & $3454 G>A$ & A1152T & gDNA vs. transcript \\
\hline \multicolumn{5}{|l|}{ ABCB11 (BSEP) } \\
\hline rs496550 & $168923202 T>C$ & $* 420 A>G$ & - & $47.8 / 53.6 / 30.2$ \\
\hline rs495714 & $168923254 C>T$ & *368G>A & - & $47.7 / 53.5 / 30.2$ \\
\hline rs473351 & $168923386 \mathrm{~T}>\mathrm{C}$ & $* 236 A>G$ & - & $62.01 / 55.5 / 68.7$ \\
\hline rs579275 & $168923856 \mathrm{~T}>\mathrm{C}$ & $3766-34 A>G$ & - & $54.6 / 53.8 / 26.3$ \\
\hline rs853772 & $168958145 G>T$ & $2179-17 C>A$ & - & $53.6 / 52.4 / 26.6$ \\
\hline rs34313070 & 168973871del & 1309-31del & - & $0.2 / 0.01 / 1.9$ \\
\hline rs4148776 & $169014372 A>G$ & $99-18 \mathrm{~T}>\mathrm{C}$ & - & $8.4 / 5.5 / 31.0$ \\
\hline \begin{tabular}{|l|} 
rs4148772 \\
\end{tabular} & $169018202 C>T$ & $-27-50 G>A$ & - & $5.3 / 3.8 / 6.1$ \\
\hline rs2193831 (ho) & $168970367 C>T$ & $1639-152 \mathrm{G}>\mathrm{A}$ & - & $56.7 / 59.7 / 55.9$ \\
\hline rs2241340 (ho) & $168971815 A>G$ & $1638+32 T>C$ & - & $57.1 / 59.8 / 56.4$ \\
\hline rs2287623 (ho) & $168973645 G>A$ & $1434+70 \mathrm{C}>\mathrm{T}$ & - & $57.2 / 59.0 / 55.8$ \\
\hline 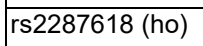 & 168986299T>C & $909-15 A>G$ & - & $69.9 / 69.3 / 82.8$ \\
\hline rs4148777 & $169013391 A>G$ & $270 \mathrm{~T}>\mathrm{C}$ & F90F & $4.6 / 3.6 / 6.8$ \\
\hline rs2287622 (ho) & $168973818 A>G$ & $1331 \mathrm{~T}>\mathrm{C}$ & V444A & $56.9 / 59.7 / 56.6$ \\
\hline rs138642043 & $168964291 C>T$ & $2093 G>A$ & $\mathrm{R} 698 \mathrm{H}$ & $0.4 / 0.3 / 0.7$ \\
\hline rs497692 & $168932506 \mathrm{~T}>\mathrm{C}$ & $3084 A>G$ & A1028A & $54.5 / 53.6 / 26.6$ \\
\hline \multicolumn{5}{|l|}{ ABCB4 (MDR3) } \\
\hline rs45549641 & $87402374 A>G$ & $3655-72 T>C$ & - & $13.5 / 8.6 / 27.5$ \\
\hline rs31653 & $87403297 A>G$ & $3508-16 \mathrm{~T}>\mathrm{C}$ & - & $87.7 / 89.5 / 97.7$ \\
\hline rs7788404 & $87418497 T>C$ & $2478+40 A>G$ & - & $9.2 / 7.7 / 18.0$ \\
\hline \begin{tabular}{|l|} 
rs31668 \\
\end{tabular} & $87423890 G>A$ & $2211+16 C>T$ & - & 89.9 / 92.4 / 93.4 \\
\hline rs1017054 & $87426695 \mathrm{~T}>\mathrm{C}$ & $2064+55 A>G$ & - & $15.2 / 8.6 / 33.5$ \\
\hline rs2230028 & $87426860 T>C$ & $1954 A>G$ & R652G & $10.5 / 7.5 / 34.8$ \\
\hline
\end{tabular}


References

1. Hirschfield GM, Heathcote EJ, Gershwin ME. Pathogenesis of cholestatic liver disease and therapeutic approaches. Gastroenterology. 2010;139(5):1481-1496.

2. Hirschfield GM. Genetic determinants of cholestasis. Clin Liver Dis. 2013;17(2):147-159.

3. Kubitz R, Droge C, Stindt J, Weissenberger K, Haussinger D. The bile salt export pump (BSEP) in health and disease. Clin Res Hepatol Gastroenterol. 2012;36(6):536-553.

4. van der Woerd WL, Houwen RH, van de Graaf SF. Current and future therapies for inherited cholestatic liver diseases. World J Gastroenterol. 2017;23(5):763-775.

5. Gudbjartsson DF, Sulem P, Helgason $\mathrm{H}$, et al. Sequence variants from whole genome sequencing a large group of Icelanders. Sci Data. 2015;2:150011.

6. Gonzales E, Taylor SA, Davit-Spraul A, et al. MYO5B mutations cause cholestasis with normal serum gamma-glutamyl transferase activity in children without microvillous inclusion disease. Hepatology. 2017;65(1):164-173.

7. Schady DA, Finegold MJ. Contemporary Evaluation of the Pediatric Liver Biopsy. Gastroenterol Clin North Am. 2017;46(2):233-252.

8. Blackmore L, Knisely AS, Hartley JL, et al. Polymorphisms in ABCB11 and ATP8B1 Associated with Development of Severe Intrahepatic Cholestasis in Hodgkin's Lymphoma. $J$ Clin Exp Hepatol. 2013;3(2):159-161.

9. Pauli-Magnus C, Meier PJ, Stieger B. Genetic determinants of drug-induced cholestasis and intrahepatic cholestasis of pregnancy. Semin Liver Dis. 2010;30(2):147-159.

10. Hu G, He P, Liu Z, Chen Q, Zheng B, Zhang Q. Diagnosis of ABCB11 gene mutations in children with intrahepatic cholestasis using high resolution melting analysis and direct sequencing. Mol Med Rep. 2014;10(3):1264-1274.

11. Pan S, Li X, Jiang $P$, et al. Variations of ABCB4 and ABCB11 genes are associated with primary intrahepatic stones. Mol Med Rep. 2015;11(1):434-446.

12. Mahdi ZM, Synal-Hermanns U, Yoker A, Locher KP, Stieger B. Role of Multidrug Resistance Protein 3 in Antifungal-Induced Cholestasis. Mol Pharmacol. 2016;90(1):23-34.

13. Putterman C, Keidar S, Brook JG. Benign recurrent intrahepatic cholestasis--25 years of follow-up. Postgrad Med J. 1987;63(738):295-296.

14. Summerskill WH. The Syndrome of Benign Recurrent Cholestasis. Am J Med. 1965;38:298305.

15. Luketic VA, Shiffman ML. Benign recurrent intrahepatic cholestasis. Clin Liver Dis. 2004;8(1):133-149, vii.

16. Tygstrup N, Jensen B. Intermittent intrahepatic cholestasis of unknown etiology in five young males from the Faroe Islands. Acta Med Scand. 1969;185(6):523-530.

17. van Mil SW, van der Woerd WL, van der Brugge G, et al. Benign recurrent intrahepatic cholestasis type 2 is caused by mutations in ABCB11. Gastroenterology. 2004;127(2):379384.

18. Campagna JD, Bond MC, Schabelman E, Hayes BD. The use of cephalosporins in penicillinallergic patients: a literature review. J Emerg Med. 2012;42(5):612-620.

19. Apter AJ, Kinman JL, Bilker WB, et al. Is there cross-reactivity between penicillins and cephalosporins? Am J Med. 2006;119(4):354 e311-359.

20. Morgan RE, van Staden CJ, Chen Y, et al. A multifactorial approach to hepatobiliary transporter assessment enables improved therapeutic compound development. Toxicol Sci. 2013;136(1):216-241.

21. deLemos AS, Ghabril M, Rockey DC, et al. Amoxicillin-Clavulanate-Induced Liver Injury. Dig Dis Sci. 2016;61(8):2406-2416.

22. Morgan RE, Trauner M, van Staden CJ, et al. Interference with bile salt export pump function is a susceptibility factor for human liver injury in drug development. Toxicol Sci. 2010;118(2):485-500.

23. Keitel V, Vogt C, Haussinger D, Kubitz R. Combined mutations of canalicular transporter proteins cause severe intrahepatic cholestasis of pregnancy. Gastroenterology. 2006;131(2):624-629.

24. Byrne JA, Strautnieks SS, Ihrke G, et al. Missense mutations and single nucleotide polymorphisms in ABCB11 impair bile salt export pump processing and function or disrupt premessenger RNA splicing. Hepatology. 2009;49(2):553-567.

25. El Sherrif $Y$, Potts JR, Howard MR, et al. Hepatotoxicity from anabolic androgenic steroids marketed as dietary supplements: contribution from ATP8B1/ABCB11 mutations? Liver Int. 2013;33(8):1266-1270. 
26. Gudbjartsson DF, Helgason H, Gudjonsson SA, et al. Large-scale whole-genome sequencing of the Icelandic population. Nat Genet. 2015;47(5):435-444.

27. Jirsa M, Bronsky J, Dvorakova L, et al. ABCB4 mutations underlie hormonal cholestasis but not pediatric idiopathic gallstones. World journal of gastroenterology : WJG. 2014;20(19):5867-5874.

28. Bull LN, Thompson RJ. Progressive Familial Intrahepatic Cholestasis. Clin Liver Dis. 2018;22(4):657-669.

29. Reichert MC, Hall RA, Krawczyk M, Lammert F. Genetic determinants of cholangiopathies: Molecular and systems genetics. Biochim Biophys Acta Mol Basis Dis. 2018;1864(4 Pt B):1484-1490. 